\title{
Morphological and Phenological Characterization of 52 Accessions of Fragaria chiloensis (L.) Duch.
}

\author{
A. Lavín ${ }^{1}$ \\ Centro Experimental Cauquenes, INIA, Casilla 165, Cauquenes, Chile \\ C. Barrera \\ Facultad de Ciencias Agrarias, Universidad de Talca, Casilla 747, Talca, Chile
}

\begin{abstract}
J.B. Retamales
Facultad de Ciencias Agrarias and Centro de Investigación en Biotecnología Silvoagrícola, Universidad de Talca, Casilla 747, Talca, Chile
\end{abstract}

\section{Maureira}

Centro Experimental Cauquenes, INIA, Casilla 165, Cauquenes, Chile

The Chilean strawberry (F.chiloensis) is one of the progenitors of the commercial strawberry $(F$. $\times$ ananassa $)$. The INIA station at Cauquenes $\left(35^{\circ} 59^{\prime} \mathrm{S} ; 72^{\circ} 20^{\prime} \mathrm{W}\right)$ has a collection of nearly 300 accessions of $F$. chiloensis that could be used for breeding purposes; but has not been properly characterized for horticultural traits. The objective was to characterize a portion of the collection from Chile, between latitudes $34^{\circ}$ and $47^{\circ} \mathrm{S}$, plus an accession from Ecuador (Lat. $01^{\circ} 00^{\prime} \mathrm{S}$ ), at the INIA-Cauquenes station for several morphological and phenological traits, so as to gather the basic information to select parents for future crossings in the scope of a breeding program to obtain improved $F$. chiloensis cultivars.

\section{Materials and Methods}

Plants were planted in the field in a sandy soil possessing a high quartz content (Cauquenes series), in late August 1998 on 30-cm-high and
This research was supported by FONDECYT Project 1980166.

1E-mail alavin@inia.cl.

80-cm-wide beds at a 40 -cm distance among plants. Plastic mulch $(80 \mu \mathrm{m}$ in thickness; white on top, black on the bottom) was used to control weeds. Although no pests were detected during the season, Systhane 40 WP (DOW AgroSciences, Midland, Mich.) was applied (10 g/100 $\mathrm{L}$ water) to control powdery mildew. Ultrasol

Table 1. Morphological characteristics of Fragaria chiloensis accessions (L.) Duch. 1998-99.

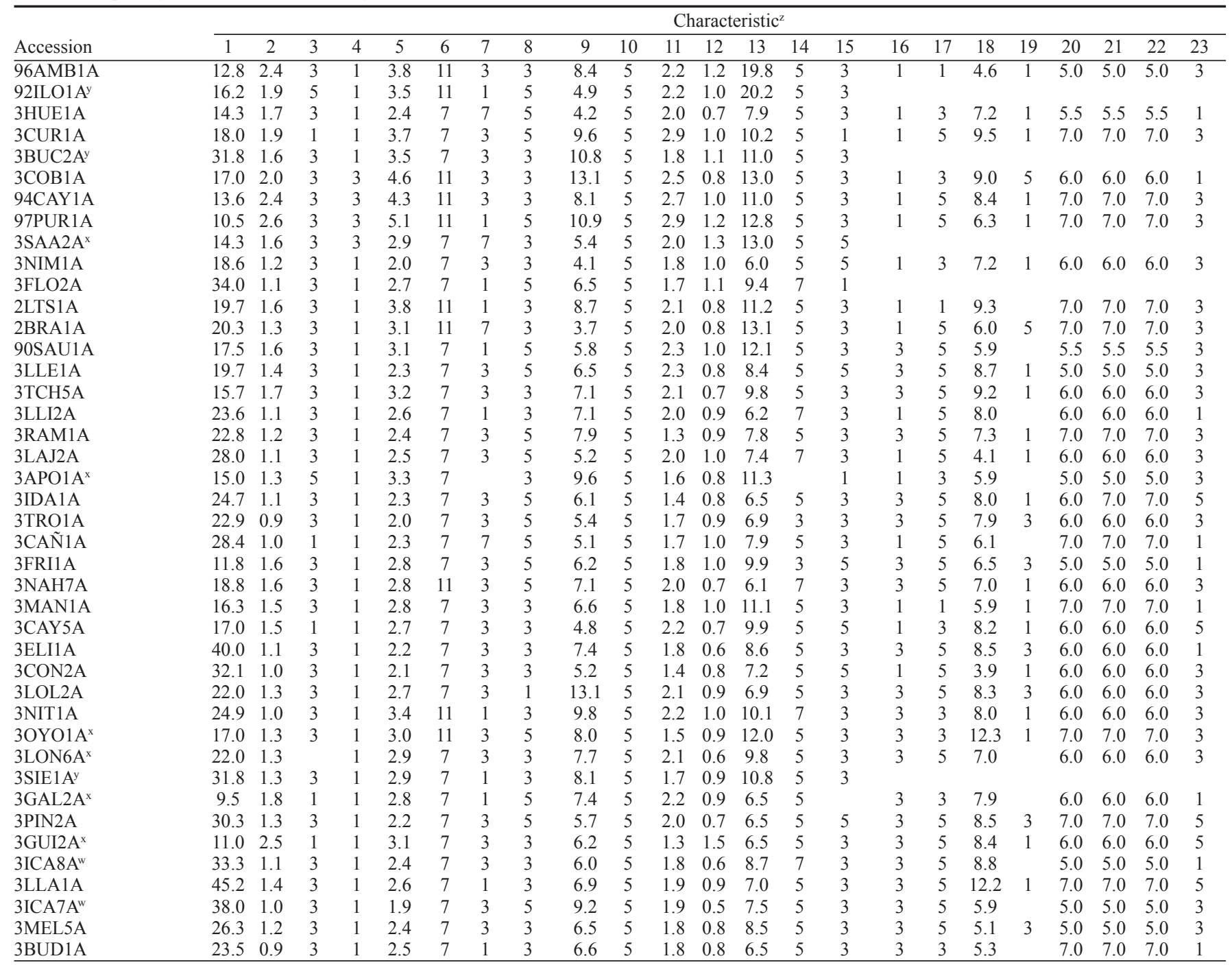




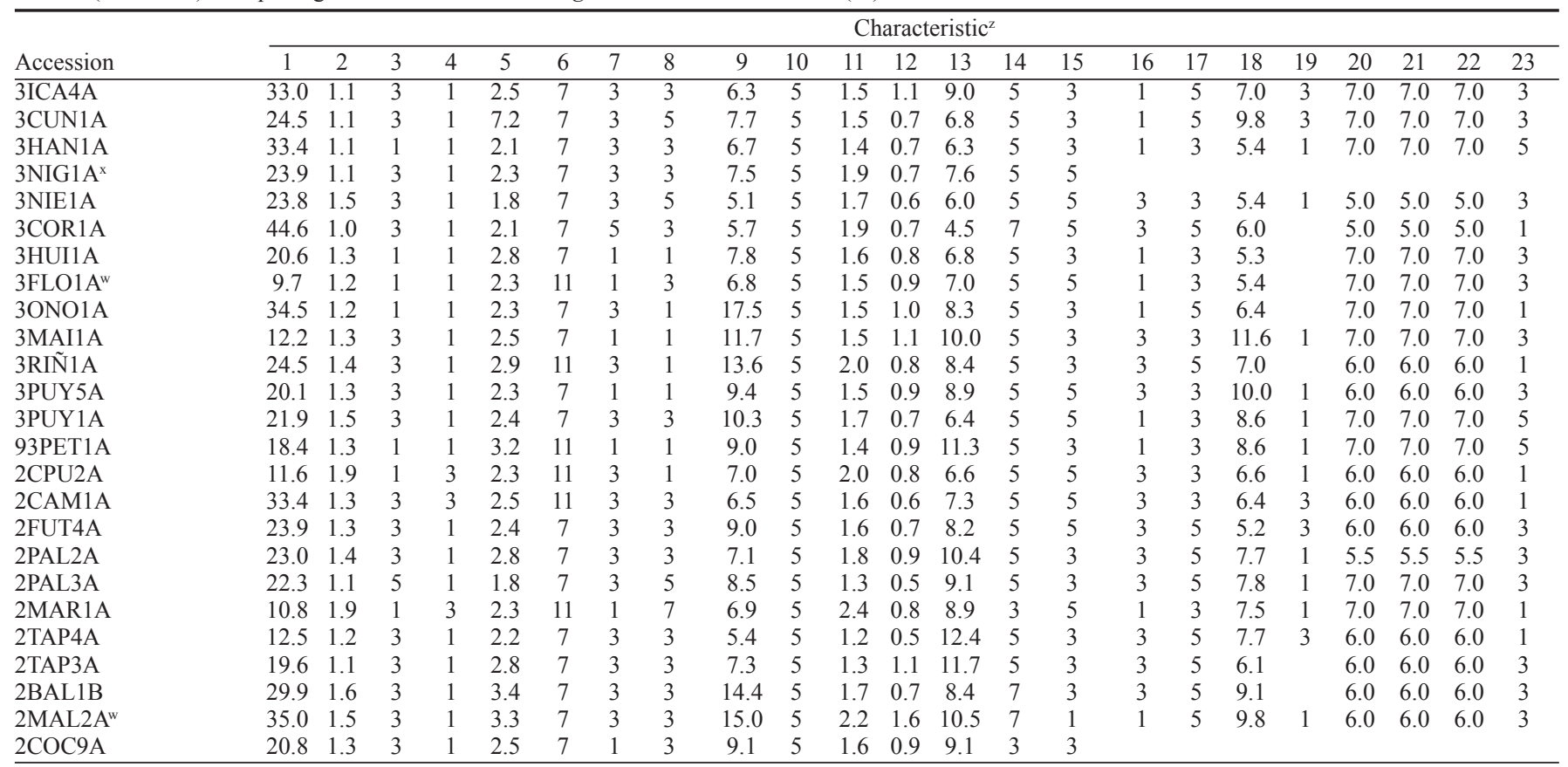

${ }^{\mathrm{z} C h a r a c t e r i s t i c:}$

1) Number of leaves

2) Petiole diameter ( $\mathrm{mm})$

3) Pubescence of leaflet abaxial side: $1=$ dense, 5) sparse

4) Leaflet orientation: 1 = apical, $7=$ admedium

5) Leaflet width (cm)

below foliage

6) Leaflet form: 1 = oblong, 11 = obovate very wide

7) Color of leaflet adaxial side: $1=$ clear green, $7=$ dark green

8) Leaflet brightness: $1=$ very bright, $7=$ opaque

9) Length of petiolule $(\mathrm{cm})$

10) Leaflet apex: $1=$ obtuse, $9=$ emarginated

11) Stolon diameter (1) (mm)

12) Stolon length $(\mathrm{cm})$

13) Stolon length to first node $(\mathrm{cm})$,

14) Vegetative habit: $1=$ very weak, $9=$ very vigorous

15) Plant growth habit: $1=$ erect, $5=$ postrate

16) Rachis branching: $1=$ high or $3=$ low

17) Inflorescence position: $1=$ over, $5=$ below foliage

18) Calyx length $(\mathrm{cm})$

19) Presence of pollen (1): $1=$ yes, $3=$ no, or $5=$ both

20) Number of petals

21) Number of sepals

22) Number of bracteoles

23) Type of calyx: $1=$ adhered, $3=$ free, or $5=$ reflex

${ }^{y}$ Accession not evaluated for inflorescence and flower.

${ }^{\mathrm{x}}$ Accession with less than 4 plants evaluated.

wVariable not considered in multivariate analysis.
(Soquimich, Santiago), a commercial $18 \mathrm{~N}-18 \mathrm{P}-18 \mathrm{~K}$ fertilizer was applied weekly through the irrigation system during the first 3 weeks of September, at a rate of $0.9 \mathrm{~g} \cdot \mathrm{L}^{-1}$. Plants were drip irrigated according to needs established through a Class Aevaporimeter. Morphological characteristics (Table 1 ), were established through weekly observations on at least 4 plants per accession. Variables were analyzed through multivariate analysis using TREE software (SAS Institute, Cary, N.C.). Cluster analysis was used to determine distances through the average method and expressed as RMS (rootmean square), using the criterion of $\mathrm{RMS} \geq 0.8$.

\section{Results and Discussion}

The multivariate analysis of morphological characteristics of vegetative organs and flowers determined nine clusters of accessions
(Fig. 1), with a mild relationship between the climatic characteristics and the zones of origin. Several accessions (3CAY5A, 3ONO1A, 3CUN1A, 2MAR1A, 3COR1A, 3CUR1A, and 97AMB1A), could not be assigned to a given cluster. 97AMB1A (collected in Ecuador), was the most different of the accessions considered; this accession was originally described by Garcilaso de la Vega in 1609 (Popenoe, 1921; Wilhelm and Sagen, 1974). Native Chilean strawberries were taken by the Spaniards from Chile to Perú and in 1557 to Ecuador; these plants have been productive for over four centuries without replanting and irrigation (Darrow, 1953; Wilhelm and Sagen, 1974). In the dendrogram (Fig. 1), this accession appears to be the most different, which agrees with the description of Popenoe (1921) when he visited Santiago and mentioned that "these plants appear quite vigorous and robust and markedly different from those observed in Huachi, Ecuador." Considering that in this experiment conditions were homogeneous for all accessions, 97AMB1A presented an intermediate growth habit. Also, the accession 3CUR1A is shown as 


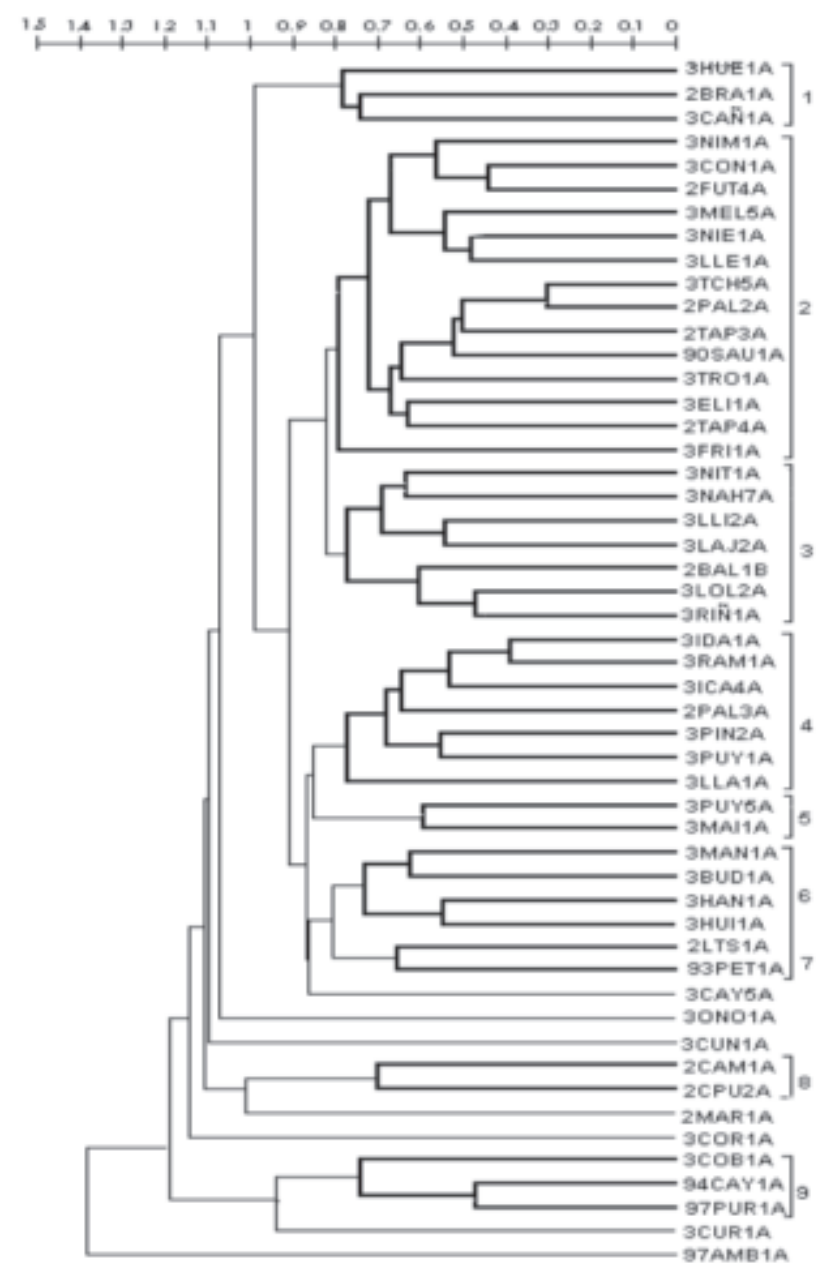

Fig. 1. Dendrogram of $F$. chiloensis accessions derived from multivariate analysis of the characteristics of vegetative organs and flowers. It shows the normalized distance from the root of the average (RMS) of the different accessions and the groups with RMS $>8$.

different from other white-fruited accessions, which coincides with the conclusions of Lavín et al. (2000).

Figure 1 also shows that most cultivated white-fruited accessions (F. chiloensis f. chiloensis) included in this analysis are separated from the red-fruited wild accessions (F. chiloensis $\mathrm{f}$. patagonica), which appear in group nine or are isolated(such as 97AMB1Aand3CUR1A). This agrees with descriptions by Staudt (1962) and Lavín et al. (2000).

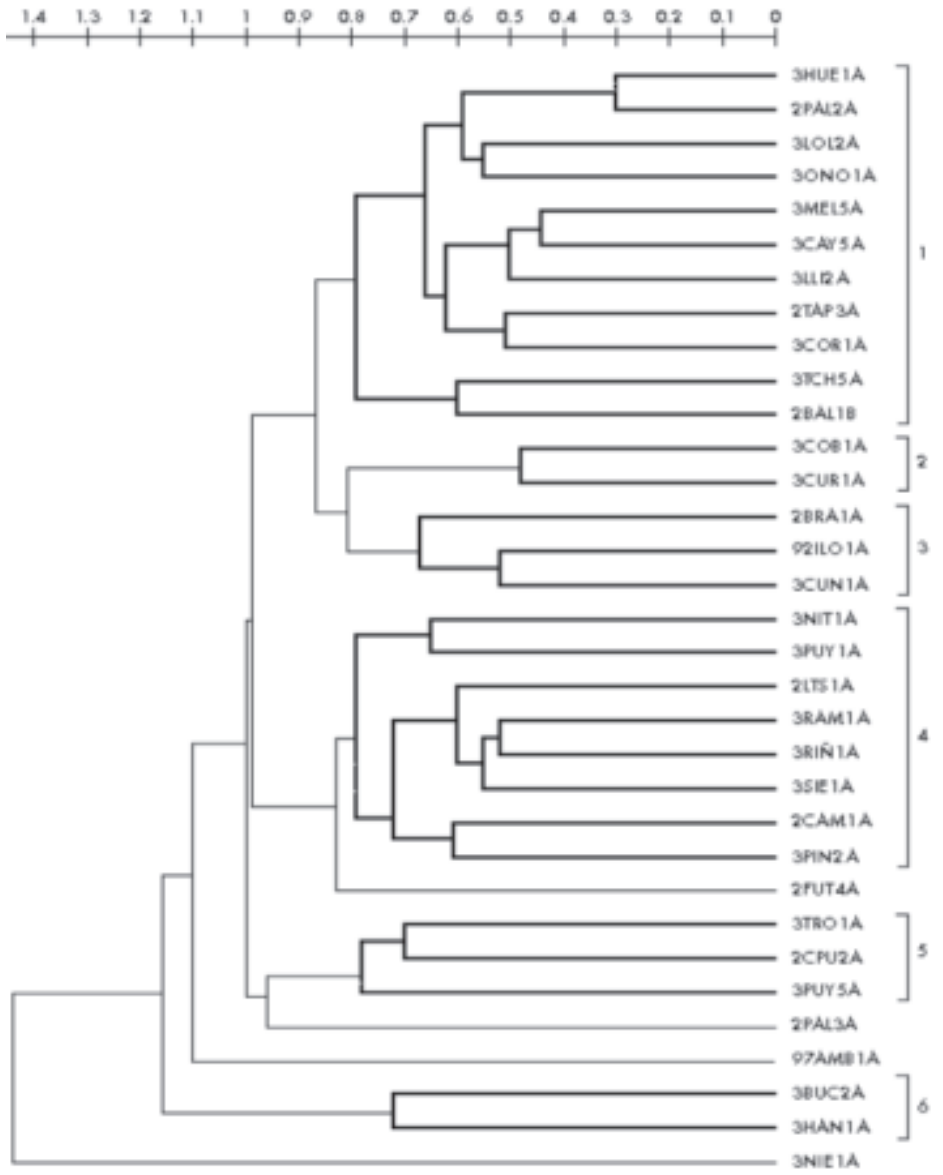

In the multivariate analysis of fruit characters (Fig. 2), all but four accessions were included in 6 clusters. The phenological characterization, based on the presence of flowers and fruits during the season, allowed the formation of four distinct groups. The most precocious accession was 3CUR1A, which started blossoming in the first week of October.

The main objective of the future breeding program will be focused on the creation of cultivars with large whitish fruits, similar to the traditional ones but with higher yield potential. The parents will be mainly chosen from the white cultivated accessions ( $F$. chiloensis $\mathrm{f}$. chiloensis) but some red fruited accessions ( $F$. chiloensis f.patagonica) will be included, since even though their bear small fruit, they have some interesting characters, such as a longer flowering period. From the results presented, it is clear that some red fruited accessions are
Fig. 2. Dendrogram of $F$. chiloensis accessions acteristics. It shows the normalized distance from the root of the average (RMS) of the different accessions and the groups with RMS $>8$.

genetically close to the white fruited ones (clusters 1 and 7, Fig. 1), so if they are crossed less variation should occur.

\section{Literature Cited}

Darrow, G.M. 1953. Strawberries in Mexico, CentralAmerica, Colombia, and Ecuador. Ceiba 3:177-185.

Lavín, A., A. Del Pozo, and M. Maureira, 2000. Distribución actual de Fragaria chiloensis (L.) Duch. en Chile. IBPGR Plan Genet. Resour. Nwsltt. 122:24-28.

Popenoe, W. 1921. The frutilla, or Chilean strawberry. J. Hered. 12:457-466.

Staudt, G. 1962. Taxonomic studies in the genus Fragaria, typification of Fragaria species known at the time of Linnaeus. Can. J. Bot. 40:869-885.

Wilhelm, S. and J. Sagen, 1974. A History of the strawberry, p. 85-104. Univ. Calif. Div. Agr. Sci. derived from multivariate analysis of fruit char- 